\title{
PROMOVENDO A APRENDIZAGEM PROFISSIONAL DO DOCENTE ATRAVÉS DE UMA COMUNIDADE DE PRÁTICA REFLEXIVA EM MOÇAMBIQUE
}

\author{
Jorge Jaime dos Santos Fringe iD1, Bento Saloio Mazuze iD 2 \\ Milton Mucuanga iD 3 e Luís Muengua iD 4
}

\section{Resumo}

O ensino superior em Moçambique enfrenta vários desafios, entre os quais a massificação que resulta em mudanças nas aspirações, estilos de aprendizagem e caraterísticas demográficas da população estudantil. Consequentemente, a nós, docentes, recai dupla pressão. Por um lado, vemos o nosso papel se estender para além da lecionação e investigação. Por outro lado, temos que melhorar a nossa competência profissional. Para tal visualizamos a reflexão como o processo indicado. A reflexão apresenta-se como o elemento essencial do desenvolvimento profissional porque possibilita que o docente, partindo de suas experiências, construa novo conhecimento e transforme as perspectivas pessoais. Estes pressupostos possibilitaram-nos conceber a presente investigação-ação. Materializando a epistemologia relacional, formamos uma comunidade de aprendizagem para refletirmos sobre nossa prática. Adotamos um estudo misto, combinando questionário e gravação de dados das reflexões. Por meio do questionário, recolhemos feedback de nossos estudantes sobre o nosso desempenho. Estes dados serviram de base para o nosso primeiro momento de reflexão sobre o nosso desempenho e iluminaram a concepção de planos de ação individuais para superar fragilidades identificadas. Após a ação de melhoria, tivemos outro momento de reflexão para partilha de progressos individuais. Fizemos a gravação de voz de todos os momentos de reflexão, que constituíram, em si, ocasiões para recolha de dados qualitativos. Os resultados mostram que a nossa comunidade de prática proporcionou espaço para melhorias no uso de material didático e na comunicação e serviu de oportunidade para partilharmos e nos tornarmos conscientes do que fazemos na nossa prática de ensino.

Palavras-chave: Aprendizagem autorregulada; Comunidade de aprendizagem; Construtivismo; Investigação-ação; Reflexão.

\section{PROMOTING LECTURER'S PROFESSIONAL LEARNING THROUGH COMMUNITY OF REFLECTIVE PRACTICE IN MOZAMBIQUE}

\section{Abstract}

Higher education in Mozambique is facing several challenges, including massification. That results in changes on students' aspirations, learning styles and demographic characteristics. Consequently, we, as lecturers, are under double pressure. On the

${ }^{1}$ Doutor em Educação, pela Universidade de Pretoria, docente na Faculdade de Educação da Universidade Eduardo Mondlane (UEM) e Director Executivo no Conselho Nacional de Avaliação de Qualidade no Ensino Superior. E-mail: jorge.fringe@gmail.com ${ }^{2}$ Doutorando em Psicologia Clinica e Cultura na Universidade de Brasília e docente na Faculdade de Educação da UEM.

${ }^{3}$ Graduado em Psicologia das Organizações na UEM e docente da Faculdade de Educação da UEM.

${ }^{4}$ Doutorando em Ciências da Educação, na Universidade do Porto, e docente na Faculdade de Educação da UEM.

(1) (1) Perspectivas em Diálogo, Naviraí, v. 8, n. 16, p. 6-24, jan./abr. 2021. 
one hand, we see our role extending beyond teaching and research. On the other hand, we have to seek improvements in our professional competence. For that purpose, reflection appears to be the most indicated process. Reflection as the essential element of professional development, it allows lecturers to build new knowledge and transform personal perspectives, starting from their experiences. These assumptions enabled us to conceive the current action-research study. Putting into practice a relational epistemology, we composed a learning community to reflect on our practice. For that purpose, we adopted a mixed method approach, combining questionnaire and audio recording of reflective data. Through questionnaires, we collected our students' feedback on our performance. Questionnaire data formed the basis for our initial reflection on our performance and shed light on the design of individual action plans to overcome identified weaknesses. After carrying out improvement action, we had other moments of reflection to share our progress in our practice. We audio-recorded all of these moments, which were, per se, occasions for collecting qualitative data. The results show that our community of practice provided floor for improvement in the use of didactic material and communication and was an opportunity for us to share and become aware of what we are doing in our lecturing practices.

Keywords: Action-research; Constructivism. Learning community; Reflection; Selfregulated learning.

\section{Introdução}

A crescente massificação e expansão do ensino superior representa um desafio às instituições do ensino superior (IES) para alargarem o leque de seus recursos, entre os quais o corpo docente, em muitos casos, composto por recém-graduados com pouca ou nenhuma experiência de lecionação a este nível. Este fato, em parte, explica o porquê de mais de $60 \%$ do corpo docente das IES Moçambicanas ter apenas a Licenciatura (MÁRIO et al., 2003; DIRECÇÃO de COORDENAÇÃO do ENSINO SUPERIOR, 2006; MINISTÉRIO da EDUCAÇÃO e CULTURA, 2006). Em alinhamento com a estratégia de formação de professores para o ensino superior (Resolução no 29/2009), nota-se uma tendência crescente de abertura de cursos de Mestrado e Doutoramento que poderão ajudar a elevar o nível de formação académica ao corpo docente. Entretanto, em geral a formação académica não proporciona ao indivíduo os conhecimentos e habilidades necessários ao exercício da profissão docente. E não existe em Moçambique um sistema de formação de docentes para o ensino superior, como ocorre noutros contextos, onde, por exemplo, países anglófonos oferecem 0 chamado Postgraduate Certificate in Higher Education, análogo à Pós-graduação em docência do Ensino Superior oferecida no Brasil. Este tipo de formação é inclusive omisso na estratégia de formação de professores para o ensino superior. Pelo que, as IES organizam iniciativas locais visando proporcionar, ao corpo docente, o desenvolvimento de habilidades de planificação, facilitação, avaliação da aprendizagem (MANDLATE, 2003). Estes compõem o conhecimento pedagógico do conteúdo (PCK), aquela amalgama especial entre conteúdo e pedagogia que pertence unicamente ao universo de professores, que distingue um professor de uma dada disciplina de um especialista dessa mesma disciplina (SHULMAN, 1987). 
A Universidade Eduardo Mondlane (UEM) oferece cursos de curta duração através do Centro de Desenvolvimento Académico (CDA). Contudo, como outro curso qualquer, estes cursos não equipam o docente para lidar com as surpresas, dilemas e situações problemáticas colocados pela prática profissional de ensino, visto que esta não apresenta problemas bem estruturados. Antes, esta coloca situações indeterminadas e desordenadas que requerem do docente uma veia mais artística do que tecnicista (SCHÖN, 1983).

A natureza incerta, rápida e eruptiva com que o corpo do conhecimento se desenvolve coloca o docente sob pressão de constantemente atualizar-se. Há quem advoga que tal atualização pudesse acontecer através de frequentes participações em cursos de curta duração. No entanto, se considerarmos a velocidade do crescimento do conhecimento, a hipótese levantada pareceria problemática. Ademais, o próprio papel do docente está em crescente e rápida expansão. Na UEM fala-se de lecionação, investigação, administração e extensão universitária. Noutros contextos fala-se de docente como desenhador de curricula, perito em tecnologias, especialista da área, avaliador, pároco da cidadania e aprendente ao longo da vida (MINISTRY OF EDUCATION, 2000). Por isso, sendo que o conhecimento profissional não é independente do contexto em que é aprendido ou do modo como é usado, defendemos um desenvolvimento profissional embebido na prática profissional e focado na resolução de problemas. Portanto aderimos a ideia de aprendizagem profissional construtiva e autorregulada. Visualizamos a reflexão como o processo instrumental que nos pode apoiar a ultrapassar algumas das preocupações encapsuladas. Pelo que, concebemos a presente pesquisa com o propósito de compreender como podemos promover a nossa aprendizagem profissional através da reflexão sobre nossas práticas de modo a melhorar o nosso desempenho. Para tal, realizamos uma experiência de desenvolvimento profissional através de uma pequena comunidade reflexiva e empregamos a investigação-ação para monitorar a nossa aprendizagem.

\section{Referencial teórico}

A prática reflexiva é amplamente reconhecida como o elemento essencial no desenvolvimento profissional (HARRISON; LAWSON; WORTLEY, 2005). Mesmo não reunindo uma definição consensual, a reflexão é foco de muito interesse e dos mais diversificados estudos na educação. Consensual é a ligação da sua origem à Dewey e Schön. Segundo Dewey (1910), um profissional, quando enfrenta situações inesperadas que provocam dúvida, inicia um processo de modificação mental da experiência de modo a identificar fatos que poderão resolver o problema subjacente. Trata-se de um processo que consiste em estudar, escrutinar e rever evidências, avaliando as implicações das diversas hipóteses e comparando os resultados teóricos. Em concordância, Schön (1983), crítico do modelo da racionalidade técnica, indica que quando algo não corre segundo as expetativas, o profissional responde através da reflexão-na-ação que envolve operações como a restruturação da compreensão, reformulação da situação-problemática e desenvolvimento de nova forma de execução. Após a ocorrência da atividade, o profissional envolve-se numa reflexãosobre-a-ação, uma espécie de análise post-mortem, através da qual ele busca extrair lições. 
A reflexão não consiste numa simples aprendizagem no vazio, mas um processo de dar significado ao que aprendemos num contexto específico de desempenho de alguma tarefa. Através da reflexão podemos identificar e criticar compreensões tácitas que tenham emergido e desenvolvido em nossas atividades rotineiras (SCHÖN, 1983). Trata-se de um processo em que examinamos e exploramos evidências de nossa prática, julgamos se as teorias pessoais são adequadas ou não e buscamos compreensões alternativas (HARRISON; LAWSON; WORTLEY, 2005). Mezirow (1990) visualiza a reflexão tanto como uma pausa para reavaliação do que a pessoa está a fazer erradamente na busca da melhor performance ou como uma avaliação ex post facto visando olhar para aprendizagem prévia com foco em pressupostos, processos ou procedimentos seguidos de resolução do problema.

No corrente estudo, abordamos a reflexão como uma série de atividades intelectuais e afetivas em que o docente se engaja para explorar suas experiências de modo a alcançar uma nova compreensão e apreciação (BOUD et al., 1985). Tais atividades são independentes de a experiência ser desconfortável ou geradora de dúvida. Através da reflexão o profissional posiciona-se melhor para lidar com as constantes mudanças circunstanciais. Pelo que, sendo orientada para ação e contextualmente embebida, não pode ser entendida como puramente interna ao docente (HARRISON; LAWSON; WORTLEY, 2005). Inspirados em Costa e Santos (2013), julgamos que a reflexão docente não pode ser entendida como uma trajetória unidimensional, mas como uma aprendizagem contínua que busca, nas vivências e experiências tanto formativas como educativas, superar os erros e criar novos modelos, sobretudo, por meio de trocas de experiências vividas conjuntamente com pares, propiciando a construção de novos conhecimentos, com impacto tanto no contexto macro da escola, assim como no micro espaço da sala de aula. Esta reflexão torna o docente inquieto em seu exercício profissional, em sua prática de sala de aulas, levando-o a procurar na coletividade soluções para os problemas identificados e permitindo que ele se torne um profissional crítico e reflexivo sobre o seu fazer, sobre o fazer dos seus colegas e sobre os acontecimentos da realidade circundante.

No modelo de aprendizagem experiencial (KOLB, 1984) a reflexão emerge com um papel significativo, dado que permite ao docente, como sujeito aprendente, estabelecer a ligação teoria-prática. Segundo Kolb (1984), a aprendizagem ocorre através de quatro estágios sequenciais, nomeadamente a experiência concreta, a observação refletiva, a conceitualização abstrata e a experimentação ativa. Este modelo pressupõe aprendentes ativos, num movimento rumo a autonomia pessoal, assumindo responsabilidade pela própria aprendizagem, que é holística e visa pontos de vista conflituantes (HARRISON; LAWSON; WORTLEY, 2005).

Neste estudo, procuramos observar e refletir em nossas experiências concretas de ensino, partindo do feedback do estudante, estabelecendo uma ponte com a conceituação abstrata, oscilando em diversos graus entre envolvimento específico e distanciamento analítico geral. Ambicionamos crescer através da aquisição incremental de habilidades que dependem de acumulação de experiências e da reflexão significativa sobre as mesmas (HARRISON; LAWSON; WORTLEY, 2005). Assim, entendemos que, para uma aprendizagem profissional efetiva, devemos nos engajar aberta e completamente na reflexão sobre nossas experiências para criarmos conceitos que integrem nossas observações numa teoria lógica (KOLB, 1984). Desta maneira, podemos usar tais teorias para decidir e resolver problemas inerentes a 
nossa prática profissional. Pelo que, subscrevemos Schön (1983) que assevera a reflexão como a epistemologia da prática profissional pois permite que desenvolvamos a nossa aprendizagem profissional através do exame de nossas práticas, de comparações, associações e inferências. Neste sentido, enquadramos a reflexão na aprendizagem construtiva, na aprendizagem situada e na aprendizagem profissional autorregulada.

Segundo o construtivismo, o sujeito aprendente constrói o seu conhecimento a partir da sua experiência. Sendo esta idiossincrática, cada docente como sujeito aprendente forma suas construções e, apenas mediante a negociação de significado, todo o grupo forma suas regras e convenções, alcançando o conhecimento viável. Assim a reflexão emerge como um exercício intrapessoal e como um diálogo interpessoal em que o docente se distancia de sua prática para avaliá-la e examinála contra um amplo contexto estrutural de modo a prever possibilidades alternativas (BARNETT, 1992). Visto que o processo é socialmente enquadrado, a construção deve ser vista como dinâmica, resultante de interação de interpretações e transformações individuais (FOSNOT, 1996).

Um aspeto distintivo que emerge das ideias apresentadas é a consideração do contexto sociocultural no processo de aprendizagem. Lave e Wenger (1991) vêm a aprendizagem como uma participação periférica legítima em comunidades de prática. Pelo que, em vez de ser vista como ocorrendo em posição de isolamento, deve ser considerada como resultando da apropriação do conhecimento em prática através de mediação e envolvimento em atividades de aprendizagem interativas e colaborativas. As comunidades de prática emergem quando os seus membros partilham significados que todos podem compreender (BISHOP, 2005). As fronteiras entre eles se dissolvem porque se vêem unidos num empreendimento comum para melhorar as suas circunstâncias (MCNIFF; WHITEHEAD, 2006). Neste estudo, visualizamos a interação como componente fundamental da aprendizagem profissional. Formamos uma comunidade de prática buscando o mesmo objetivo, nomeadamente refletir criticamente sobre nossas práticas de ensino, partilhando conhecimento e desenvolvendo processo de aprendizagem ativa e colaborativa. Criamos espaço para construção do nosso conhecimento enquadrado no nosso contexto de trabalho em confronto com o conhecimento existente fora do grupo (CONNOLLY, 2008). Reconhecemos, como crucial para o sucesso da nossa aprendizagem colaborativa, a identificação de atividades autênticas e diretamente relevantes para nós porque levanos a conectar as novas habilidades com a nossa prática profissional (TAYLOR et al., 2007). Assim cada membro adota este contexto como uma oportunidade para partilhar o peculiar conjunto de necessidades e experiências.

Como comunidade de prática constituímos uma arena para confrontação das nossas compreensões, gerando, não apenas consensos, mas também conflitos e controvérsias que, por sua vez, proporcionam explicações, justificações e busca de nova informação (VAN BOXTEL; VAN DER LINDEN; KANSELAAR, 2000). Legitimamos o conhecimento como emergente da anuência entre os membros da comunidade de docentes num ambiente criativo, democrático, de apoio mútuo, livre de desequilíbrios de poder e que contribui para um crescente senso de colegialidade.

Igualmente como comunidade de prática, onde ocorre muita colaboração e a partilha, reconhecemos a necessidade de tornar a prática docente menos solitária. Visualizamos nesta, enquanto desafio ao desenvolvimento profissional docente, o potencial contributo para aprimoramento do conhecimento teórico e prático, 
projetando mudanças de posturas, reconfigurações e adequações nas nossas práticas pedagógicas (PRYJMA; OLIVEIRA, 2016). Vemos como obsoletos os modelos em que peritos passam os princípios da arte aos novos. Acreditamos que a prática docente é tão crescentemente complexa e inerentemente difícil que mesmo os peritos não são capazes de facilmente apresentar respostas, muitas vezes requerendo e se beneficiando de conselhos e apoio dos colegas (HARGREAVES; FULLAN, 2000). Reconhecemos a aprendizagem profissional como bidirecional em que 0 conhecimento individual do docente é criado pessoalmente através da interpretação, assimilação e reconstrução do conhecimento previamente existente (FOSNOT, 1996).

O conceito de comunidade de prática, distintivo da aprendizagem situada, rejeita os tradicionais métodos de ensino baseados na transmissão de conceitos abstratos, desconectados da realidade e explorados em livros. Esta abordagem visualiza a aprendizagem como embutida e animando a prática profissional e vê a prática como dando forma a aprendizagem. Neste estudo, aderimos a aprendizagem situada porque entendemos que o aspeto central da nossa aprendizagem profissional é que procuramos nos tornar melhores profissionais aprendendo a partir da prática, não aprendendo sobre esta prática (BROWN; DUGUID, 1991). Buscamos extrair mais apoio, informação e senso do que é plausível de nossos colegas imediatos. Ajudamonos a gerar desenvolvimento colaborativo e troca de perspetivas em questões relevantes à nossa prática e que, por isso, possam beneficiar aos nossos estudantes. Pelo que, a planificação e a implementação de atividades que visam o nosso crescimento ocorrem como resultado de esforço conjunto.

No presente estudo, autorregulamos a nossa aprendizagem profissional construindo significados e ajustando as nossas ideias e ações aos objetivos que o contexto nos coloca. Desafiamo-nos mutuamente a refletir sobre nossas práticas de modo a identificarmos o que devemos melhorar. Ao refletirmos em colaboração, partilhamos soluções práticas para problemas concretos levantados por nossos estudantes, ajudamo-nos a desenvolver atitudes positivas face aos desafios profissionais que enfrentamos e nos energizamos para sermos mais efetivos na nossa prática. Monitoramos este esforço por meio da investigação-ação. Assim, no decurso do estudo planificamos, estabelecemos metas, implementamos ações, geramos recursos e autoavaliamos a nossa aprendizagem (ZIMMERMAN, 1990). Portanto, concordamos que o desenvolvimento profissional é um processo que envolve sequencialmente a geração de ideias que possam ser aplicadas ao ensino, experimentação dessas ideias, discussão colegial da sua viabilidade e implicações e adoção de práticas emergentes (EVANS, 2002). Deste modo, desfrutamos da liberdade de experimentar a significância situacional (BOEKAERTS, 2002), refletir, discutir e reduzir a diferença de poder entre nós (MEZIROW, 1997). Desta maneira, propiciamos a ocorrência de aprendizagem significativa e profunda facilitada pela discussão, diálogo, exploração propositada, argumentação, análise e conversas informais (CONNOLLY, 2008). Estes processos estão associados ao esforço individual de cada um de nós, como sujeito aprendente, para produzir conhecimentos elaborados e explicações coerentes na pretensão de ser compreendido pelos colegas.

\section{Metodologia}

Decorrente da nossa intenção de investigar a nossa prática docente, recorremos à investigação-ação. Esta é uma forma de pesquisa poderosa e 
libertadora (MCNIFF; WHITEHEAD, 2006), entre outras, por possibilitar-nos a busca de novas ideias acerca de experiências familiares (WINTER, 1996). Por isso, contribui para o nosso desenvolvimento profissional. Engajamo-nos numa aprendizagem colaborativa, através de uma abordagem crítica e autocrítica, de modo a explorarmos o potencial da investigação-ação para avaliar nossos esforços, transformar a nossa prática com base em informação recolhida sistematicamente, enquanto contribuímos para a construção do conhecimento (MCNIFF, 1988; WINTER, 1996). Neste sentido, julgamos este estudo emancipador (MCNIFF; WHITEHEAD, 2006).

Ao adotarmos a investigação-ação, julgamos desnecessária a divisão entre pesquisadores e pesquisados porque todos somos privilegiados em ambos papéis e em posição avantajada para beneficiarmos a nossa prática através de sua exploração sistemática (MCKERNAN, 2008). Vemo-nos como parte da situação que investigamos e interrogamo-nos como podemos melhorar e trabalhamos nesses aspetos (MCNIFF; WHITEHEAD, 2006). Pelo que, procuramos construir um conhecimento conectado num contexto em que as nossas preocupações, interesses e agenda como investigadores tornam-se nossas preocupações, interesses e agenda como investigados (BISHOP, 2005). Como membros internos julgámos que podíamos realizar a pesquisa de um modo mais sensível, entre outras razões porque teríamos acesso natural ao ambiente, habilidade para ler sinais não-verbais e fazer perguntas significativas (BISHOP, 2005).

Aderimos ao pressuposto ontológico segundo o qual existem múltiplas realidades e, para compreender e melhorar, escolhemos a nossa realidade. Reconhecemos que entre nós não existe distribuição desigual de poder. Antes, anuindo com McNiff e Whitehead (2006), visualizamo-nos como igualmente poderosos, sendo cada um potencialmente capaz de falar por si e exercer a própria diligência, e concordamos em interagir uns com os outros nestes termos. Materializamos a epistemologia relacional porque vemos o nosso conhecimento como construído por nós que estamos embutidos, incorporados e relacionados uns com os outros (BISHOP, 2005). Por isso, estamos profundamente envolvidos na cocriação de novas identidades e acreditamos que este processo de autocriação transformativa pode influenciar como trabalhamos coletivamente para bem-estar pessoal e coletivo sustentável (MCNIFF; WHITEHEAD, 2006). A sustentabilidade decorre de erradicarmos as relações de poder entre peritos e aprendizes para desenvolvermos formas mais democráticas de trabalho, criando e implementando nossas ideias em vez de apenas aceitarmos e implementarmos as ideias dos outros. Desenvolvemos o sentido de nós como agentes com voz própria, não como resultado de um investigador nos permitir ou nos empoderar. Pelo que, como diz Bishop (2005), nas relações que estabelecemos nesta comunidade não há lugar para conceitos como distância, destacamento e separação. Antes, o nosso foco está na nossa contínua evolução.

Nesta investigação-ação adotamos uma abordagem de métodos mistos, dada a nossa pretensão de complementar os pontos fortes das abordagens qualitativa e quantitativa. A abordagem quantitativa nos proporcionou a extensão, enquanto a qualitativa, buscando significados, proporcionou a profundidade dos fenómenos. 0 nosso espírito de indagação permitiu que nos tornássemos investigadores da nossa aprendizagem, não só tentando entender a nós como aprendentes, mas tentando compreender as perspetivas de nossos estudantes (WILLIAMS, 1992, apud HALENFABER, 1997). 
Subdividimos este estudo em dois momentos. No primeiro momento, através da administração de questionário, fizemos o levantamento da avaliação dos estudantes sobre o nosso desempenho em diversas áreas, tais como planificação, organização, facilitação, avaliação e relacionamento. O segundo momento consistiu nos nossos momentos de reflexão, planificação e ação iluminadas pelos resultados do questionário aplicado aos estudantes. Cada membro da equipa procedeu a reflexão sobre seus resultados, planificou ações subsequentes e partilhou a sua leitura com os demais co-aprendentes. Porque foi gravado, este momento constituiu, em si, uma ocasião de recolha de dados qualitativos. Estas reflexões em assembleia (BABBIE; MOUTON, 2001) possibilitaram a participação e colaboração que tipificam a investigação-ação (MCNIFF, 1988). O diálogo desempenhou um papel-chave porque é reflexivo e empoderador (BABBIE; MOUTON, 2001). Tal como em grupos focais, houve combinação de dados orais e observacionais, permitindo a captura de discussões e elementos não-verbais (BABBIE; MOUTON, 2001).

\section{Resultados e discussões}

\subsection{Dados quantitativos}

Responderam ao questionário 131 estudantes de quatro (4) turmas, sendo uma do curso de Licenciatura em Língua de Sinais de Moçambique e três (3) de Licenciatura em Psicologia. Duas (2) turmas eram do regime laboral e as outras do pós-laboral. Os dados percentuais, apresentados no Quadro 1, mostram uma clara apreciação positiva no cumprimento de horário, onde cerca de $93 \%$ avaliou como bom ou muito bom. O mesmo ocorre em Postura ética do professor (89\%), Resposta às questões ( $87 \%$ ) e Clareza na explicação (79\%). Ocorre igualmente satisfação com outros itens. Porém, nestes, uma parte dos estudantes nos classificou como regular e mau. Em três (3) itens há classificação de mau, nomeadamente Cumprimento de horário (2\%), Atenção às preocupações (2\%) e Aproveitamento do tempo definido para aula $(1 \%)$.

\section{Quadro 1: Avaliação pelo estudante da postura do docente}

\begin{tabular}{|l|c|c|c|c|c|}
\hline \multicolumn{1}{|c|}{ ITEM } & $\begin{array}{c}\text { Muito } \\
\text { mau }\end{array}$ & Mau & Regular & Bom & $\begin{array}{c}\text { Muito } \\
\text { bom }\end{array}$ \\
\hline Relacionamento com estudantes & 0 & 2 & 20 & 39 & 38 \\
\hline Clareza na explicação & 0 & 1 & 21 & 43 & 36 \\
\hline Adequação dos métodos & 0 & 1 & 17 & 45 & 37 \\
\hline Aproveitamento do tempo & 1 & 3 & 17 & 40 & 40 \\
\hline Diversidade de recursos didáticos & 0 & 2 & 30 & 45 & 23 \\
\hline Objetividade da avaliação & 0 & 4 & 23 & 39 & 35 \\
\hline Análise conjunta dos resultados & 0 & 3 & 27 & 38 & 31 \\
\hline Incentivo à participação & 0 & 2 & 19 & 35 & 43 \\
\hline
\end{tabular}

Fonte: Elaborado pelos autores (2020).

O Quadro 2 apresenta os resultados da avaliação do nosso desempenho no processo de facilitação da aprendizagem. Estes resultados mostram apreciação positiva pelos estudantes da apresentação sequencial da matéria ( $95 \%$ indicaram 
que acontece frequentemente ou sempre), planificação das aulas (93\%), apresentação lógica da matéria (93\%), conhecimentos da disciplina (87\%) e segurança na lecionação (86\%). Em geral, os estudantes fizeram uma avaliação positiva em todos os itens. No entanto nos outros o nível de satisfação situa-se abaixo dos $75 \%$, com a indicação de que os referidos comportamentos ocorrem às vezes, raramente ou nunca.

Quadro 2: Avaliação pelo estudante do desempenho do docente

\begin{tabular}{|l|c|c|c|c|c|}
\hline \multicolumn{1}{|c|}{ ITEM } & Sempre & Frequent. & As vezes & Raram. & Nunca \\
\hline Conhecimentos da disciplina & 64 & 23 & 12 & 0 & 2 \\
\hline Segurança na lecionação & 57 & 29 & 12 & 0 & 2 \\
\hline Ligação teoria-prática & 45 & 30 & 23 & 1 & 2 \\
\hline Alternativas para explicar & 47 & 28 & 22 & 2 & 1 \\
\hline Identificação das deficiências & 22 & 27 & 32 & 10 & 9 \\
\hline Feedback construtivo & 46 & 27 & 20 & 5 & 1 \\
\hline $\begin{array}{l}\text { Apresentação lógica da } \\
\text { matéria }\end{array}$ & 75 & 18 & 5 & 1 & 1 \\
\hline $\begin{array}{l}\text { Apresentação sequencial da } \\
\text { matéria }\end{array}$ & 71 & 24 & 2 & 2 & 1 \\
\hline
\end{tabular}

Fonte: Elaborado pelos autores (2020).

\subsection{Dados qualitativos}

Conforme mencionamos previamente, realizamos esta pesquisa em dois momentos, nomeadamente o da administração do questionário aos estudantes, e o da reflexão, planificação e ação. Na apresentação dos resultados procedemos a separação entre dados quantitativos e qualitativos, não só para demonstrar esta diferenciação de momentos, mas também porque trabalhamos com dados que, mesmo sendo complementares, não são mescláveis. Os dados qualitativos consistem em dois grupos, nomeadamente a análise do conteúdo das reflexões alimentadas pelos resultados da aplicação do questionário aos estudantes e os dados da reflexão sobre a ação de aprendizagem profissional em que estivemos envolvidos.

\subsubsection{Reflexões sobre o resultado da auscultação aos estudantes}

A auscultação feita aos estudantes, através da administração de questionário, nos possibilitou a determinação de nossas necessidades de aprendizagem profissional e o estabelecimento de como tais necessidades podiam ser satisfeitas. A este propósito, MCPR-1 avançou que "a auscultação permitiu perceber o tipo de estudantes que tenho na sala de aula, ou melhor, o tipo de professor que os estudantes gostariam de ter".

Entendemos este exercício como um mecanismo de apropriação da nossa aprendizagem profissional. Esta representa o valor que colocamos em nós mesmos, enquanto aprendentes, com autonomia, poder, voz e responsabilidade de organizar a nossa aprendizagem e com engajamento ativo em discussões e decisões sobre a mesma. Estamos perante uma situação em que desfrutamos a liberdade de duvidar, questionar, desafiar e argumentar sobre qualquer coisa e sobre tudo que nos pareça 
conveniente. Deste modo, dispomos de um considerável controlo sobre como decorre a nossa aprendizagem. Portanto, não nos posicionamos como recipientes passivos de instruções concebidas por quem desenhou o currículo. Pelo contrário, procuramos nos estimular mutuamente para determinarmos como podemos satisfazer as nossas necessidades.

Os estudantes são os outros na situação sobre a qual estávamos a refletir. O seu feedback foi um importante estímulo para nossa reflexão, visto que nos proporcionou o conhecimento das suas perspetivas e sentimentos, o que nos levou a fazer a ligação entre nossas teorias e práticas, entre princípios e comportamentos. Com eles tivemos uma espécie de diálogo que nos proporcionou uma ideia refinada do que eles julgavam que devíamos melhorar nas nossas práticas. Informou-nos sobre a necessidade de nos engajarmos numa análise profunda e ampla de aspetos específicos habitualmente tidos como certos. Foi neste sentido que MCPR-2 disse

A auscultação contribuiu significativamente para a melhoria do meu desempenho pedagógico e profissional, na medida em que, num primeiro plano, constituiu-se como uma plataforma de diálogo com os estudantes [...] Em segundo plano, permitiu-me, através das respostas dos estudantes, colher as sensibilidades destes no que tange a minha atuação performativa na condução das aulas.

Relativamente à administração de questionários aos estudantes, reconhecemos a sua importância e pertinência, visto que nos familiariza com a avaliação que os estudantes fazem de nossa postura e desempenho, levando a uma autoanálise. Por outro lado, esta possibilita que os estudantes compreendam a sua importância, e se percebam como parte integrante e ativa do processo de ensino e aprendizagem. Portanto, esta "conversa" com os estudantes contribuiu para a nossa construção, reconstrução e entendimento sobre questões que envolvem o nosso cotidiano profissional, constituindo um ambiente propício para a reflexão e o diálogo necessários para a aprendizagem profissional (PRYJMA; OLIVEIRA, 2016).

Os dados quantitativos mostram que grande parte das respostas dos estudantes se situavam entre as classificações médias ou neutras (regular, na primeira parte, e às vezes, na segunda) e as classificações positivas (bom/muito, bom e frequentemente/sempre). Ainda que as classificações negativas (mau/muito, mau e raramente/nunca) tenham sido escassamente empregues, reconhecemo-las, juntamente com as classificações médias, como indício da necessidade de melhoria. Como disse um dos nossos colegas, o regular está na eminência do mau. Neste sentido, ele avançou que

[...] a verdade é que é preciso continuar a melhorar a situação do regular porque não é boa. Apesar de não serem tantos, mas quando se chega a ter regular significa que alguma coisa não está bem... é preciso melhorar este aspeto...relativamente aos outros, se eu puder manter, melhor... mas eu se puder melhorar cada vez mais... ótimo (MCPR-2).

Essencialmente, nesta primeira fase as nossas reflexões gravitavam em torno das avaliações que os estudantes faziam de nós. Reconhecíamos, sobretudo, a legitimidade das críticas que faziam como matéria que merecia nossa atenção. Neste sentido, MCPR-1 disse que "concordo com a avaliação e é crítica mesmo... quanto aos 
gráficos e tabelas confesso que mesmo eu tenho que aprender". Enquanto MCPR-2 dizia que em relação à:

[...] diversidade de recursos didáticos tenho cerca de $1 / 3$ que respondeu no intervalo de regular ao muito mau... não pretendo justificar, mas talvez tenha sido a metodologia que adotamos no desenvolvimento das próprias aulas, talvez também a natureza dos conteúdos abordados na disciplina possa ter remetido os estudantes a perceberem que há necessidade de diversificar quer em termos de material didático ou em termos de metodologia (MCPR-2).

Houve situações em que as nossas reflexões eram remetidas ao próprio instrumento, no sentido de o melhorarmos. As afirmações a seguir transcritas são exemplos de tal necessidade

[...] percebi a necessidade de clarificar a questão na ficha de avaliação e preciso clarificar essa questão de identificação das deficiências porque em algum momento os estudantes podem não ter percebido exatamente o que deviam responder ou o que se propunha entender (MCPR-2).

Há duas questões aqui... que pode ter desencaminhado talvez a perceção do estudante em relação ao que se pedia porque apresentar de forma lógica uma matéria, estamos a falar de ciência, e obedecer uma sequência não é, e esta sequência acaba nos remetendo de forma inversa a lógica do processo ou das abordagens que estiverem a ser desenvolvidas (MCPR-3).

Mezirow (1990) indica que a reflexão tem foco analítico nos conteúdos, processos e procedimentos de uma experiência que pode ajudar o profissional a decidir como atuar em ocasiões futuras. Nalguns momentos, nesta comunidade corroboramos a ideia acima quando embarcamos naquilo que Conway (2001) chamou de reflexão antecipatória, olhando para o futuro fundamentado no conhecimento do passado, empregando pontos de vista do presente. Neste sentido, começamos a fazer planos para o futuro, como o ilustra a transcrição seguinte

[...] poderei ter figuras que me permitam satisfazer estes aspetos, acho que são aspetos que não estávamos a ter em conta durante o trabalho, mas eu acho que com um pouco mais de esforço conseguiremos trazer, em algum momento e em alguns conteúdos, aspetos ligados às figuras... eu pessoalmente estou a prestar atenção para o segundo semestre... (MCPR-2).

\subsubsection{Reflexões sobre aprendizagem profissional}

Tal como indicamos na metodologia, após a recolha do feedback dos estudantes, cada membro da comunidade procedeu à reflexão sobre seus resultados, planificou e implementou ações subsequentes. Posteriormente houve partilha de progressos alcançados que apresentamos nas páginas que se seguem.

\subsubsection{Melhorias ocorridas}

Desenvolvimento profissional é um processo em que o docente revê suas crenças e ideias, fortalece suas práticas de lecionação e avalia a mudança. É uma evolução sequencial que consiste no reforço dos conhecimentos, melhoria de habilidades e procedimentos pelo docente (EVANS, 2002), geração, experimentação e discussão de ideias na perspetiva de melhoria da aprendizagem do estudante. 
Os elementos-chave do Conhecimento Pedagógico do Conteúdo (PCK) são, por um lado, conhecimento de representações do conteúdo específico e das estratégias instrucionais e, por outro, o entendimento das dificuldades de aprendizagem e as conceções dos estudantes de um conteúdo (SHULMAN, 1986). Docentes empregam diferentes tipos de materiais tal como aparecem definidos nos programas curriculares, o que não obsta que busquem outros materiais ou métodos e os empreguem de forma integrada. Seu emprego adequado está associado, entre outros, à promoção de uma aprendizagem profunda e ao crescente interesse pela matéria. Neste sentido, na nossa comunidade de prática ocorreram melhorias em duas categorias, nomeadamente, uso de material didático e comunicação. Relativamente ao material didático, MCPR-2 disse:

\begin{abstract}
Sinto que houve melhorias no que tange a adoção de material didático auxiliar, quer seja de natureza lúdica/experiencial ou visual, visto que um número considerável de estudantes se referiu à necessidade de investir... no emprego de tabelas, gráficos, figuras nas aulas ou na promoção da interação entre estudantes. Este fato é consubstanciado pela adoção de meios materiais visuais tais como cartazes (MCPR-2).
\end{abstract}

Uma das competências mais importantes que um docente deve ter é a comunicação, visto que facilitar a aprendizagem é comunicar. Quando a comunicação é efetiva, o processo de ensino-aprendizagem torna-se significativo e frutífero (MALEK et al., 2016). Em contraponto, a sua falha ou ausência pode dificultar a gestão do ambiente de aprendizagem (HAN; TOSTEN, 2016), podendo tornar a aula monótona, reduzir o interesse e a motivação do estudante pela aprendizagem (MALEK et al., 2016). A maioria de docentes em início de carreira experimentam dificuldades para estabelecer uma comunicação efetiva com os estudantes (HAN; TOSTEN, 2016). Eventualmente por isso, MCPR-1 disse que "Houve melhorias da linguagem e na comunicação facial... linguagem mais afável que vai ao encontro da expetativa do estudante. "

\title{
4.2.2.2. Procedimentos para melhoria
}

Através da aprendizagem profissional, o docente busca adquirir ferramentas para melhorar a qualidade do ensino-aprendizagem e desenvolver cultura de aprendizagem ao longo da vida, num processo progressivo. Em geral esta aprendizagem inicia com a auto-consciencialização, progride para confrontação de pressupostos até a exposição de conceções alternativas de ensino. Entretanto, a prática mostra a ocorrência de diversas possibilidades. Na nossa comunidade de aprendizagem profissional observamos três estratégias metodológicas novas: interação com colegas, participação ativa do estudante e redução de críticas diretas.

A interação com colegas materializa o construtivismo social, concretizando que a forma como adquirimos conhecimentos, pensamos e interpretamos o mundo é determinada por nossa experiência social e, segundo Fosnot (1996), emerge de um processo dinâmico de negociação de interpretações individuais. Assim, visualizamos a aprendizagem profissional como resultante do diálogo em que a pessoa se distancia de suas perspetivas e realizações para examiná-las à luz do contexto, num quadro amplo, a fim de identificar possíveis alternativas (BARNETT, 1992). Esta abertura para os docentes discutirem livre e abertamente seus entendimentos de teorias educacionais e suas experiências de ensino possibilita o seu empoderamento. 0 
diálogo informa ao docente sobre a necessidade de engajamento numa análise ampla e profunda de assuntos da própria prática tidos como dados adquiridos. Dois membros realçaram a interação como procedimento de melhoria. Neste sentido, um mencionou a "troca de experiências com os docentes do Departamento durante o semestre e pesquisas de novas formas de estar no processo de ensinoaprendizagem" (MCPR-1). O outro referiu que

[...] este exercício vincou o princípio de que no desempenho da atividade docente o professor deve, numa ação contínua e permanente, procurar dinamizar as suas práticas através de uma cultura de trabalho em equipa e de partilha permanente das suas experiências ou preocupações... (MCPR-2).

O esforço do docente para promover a participação ativa do estudante enquadra-se no PCK que representa aquele conhecimento profissional que distingue o professor de um especialista da mesma disciplina (SHULMAN, 1986). Com frequência, docentes empregam diferentes tipos de material curricular dentre os quais selecionam os métodos mais adequados. Consubstanciando a importância de os docentes se tornarem conscientes da possibilidade de escolha de outros métodos de aprendizagem alternativos disponíveis, MCPR-3 indicou que "passei a adotar estratégias metodológicas que privilegiam a participação ativa do estudante, no sentido de torná-lo agente que intervém e contribui ativamente no processo de construção do conhecimento".

Como vincamos nos parágrafos precedentes, é crucial que o docente disponha de boas habilidades de comunicação, visto que a sua efetividade se associa à aprendizagem significativa. Ambientes severos, ameaçadores ou subtilmente intimidatórios reduzem a autoestima, o pensamento independente, enfraquecem a aprendizagem (EKPO et al., 2009) e podem resultar em barreiras emocionais ou interpessoais. Pelo que, o docente deve promover um clima de aprendizagem positivo de modo a proporcionar a satisfação das necessidades emocionais dos estudantes, elevando o desempenho académico (EKPO et al., 2009). O docente deve ser sorridente, paciente e tolerante (CALISAN; YESIL, 2005, apud HAN; TOSTEN, 2016), para estimular no estudante a motivação, o empreendedorismo e a disponibilidade para buscar esforços suplementares para resolver problemas. Relatando a sua mudança rumo a estes preceituados, MCPR-1 disse que

No relacionamento professor-aluno passei a adotar um princípio de suavidade linguística... Mudança de estratégias de ensino, adotando as mais próximas dos estudantes... evitar críticas diretas durante os seminários, limitando-me a fazer síntese no fim de cada apresentação (MCPR-1).

\subsubsection{3. Áreas com necessidade de melhoria}

O desenvolvimento profissional é uma forma de melhorar a qualidade do ensino e aprendizagem do docente e de desenvolver cultura de aprendizagem ao longo da vida (NICHOLS, 2000). É um processo que se fundamenta na reflexão do profissional sobre a sua prática, permitindo examinar as suas teorias implícitas, seus esquemas de funcionamento, suas atitudes, num processo constante de autoavaliação que, por sua vez, passará a orientar sua ação (IMBERNÓN, 2001, apud PRYJMA; OLIVEIRA, 2016). Através desta comunidade, assumimo-nos como aprendentes ao longo da vida e procuramos abraçar modos de ensinar refletivos (WILLIAMS, 1992). 
Materializamos esta intenção através da investigação-ação que é um processo contínuo, em que quando alcançamos um ponto provisório onde nos sentimos satisfeitos, levantam-se novas questões (MCNIFF; WHITEHEAD, 2006). Desta forma, duas áreas emergem como sendo aquelas em que ainda há necessidade de melhorias, nomeadamente a diversificação de recursos didáticos e adoção de metodologias de ensino orientadas para turmas numerosas.

Segundo Hogan, Rabinowitz e Craven (2003), os docentes mais novos, quando pensam sobre a sala durante a planificação das estratégias de instrução, tendem a pensar na turma como um todo, não pensando em termos de estudantes individuais. Assim, se diferenciam dos especialistas que pensam na turma como composta por individualidades únicas e com necessidades específicas determinadas por diferenças em estilos de aprendizagem, preferências e antecedentes académicos. Consequentemente diversificam pouco as estratégias de ensino visto que não têm considerado aspetos como caraterísticas do edifício e equipamento disponíveis, habilidades ou conhecimento prévio dos estudantes (HOGAN; RABINOWITZ; CRAVEN, 2003), o que parece consubstanciar a posição de MCPR-2 ao enfatizar:

Tendo em conta a avaliação feita pelos estudantes, sinto que preciso melhorar/investir cada vez mais nos aspetos relacionados com a diversidade de recursos didáticos, aprimorar as estratégias/mecanismos adotados para materializar os índices motivacionais através de ações concretas que permitam elevar os níveis de envolvimento dos estudantes (MCPR-2).

Se o processo de formação de um profissional em geral não prepara o sujeito para todas as situações da prática com que ele se irá deparar, o desafio de turmas numerosas e sua gestão talvez sejam daquelas situações para as quais menos ocorre preparo. Docentes em início de carreira, e não só, precisam de ganhar habilidades e confiança necessárias para ensinar muitos estudantes numa sala de aulas (MARAIS, 2016). Pelo que MCPR-1 disse que:

Na relação pedagógica, dado o número maior de estudantes em cada turma, devo inovar, ou seja, pesquisar novos métodos que possam permitir mediar os conteúdos temáticos com mais eficácia e produtividade nos resultados (MCPR2).

Notamos aqui a preocupação em melhorar no trabalho com turmas numerosas, provavelmente devido a consciência da série de desafios que as turmas numerosas colocam, tais como a dificuldade de promover a aprendizagem ativa, colocar questões de ordem superior (higher-order questions), diferenciar a atenção e o feedback a todos os estudantes, gerir o barulho e a inquietude.

\section{Considerações finais}

O desenvolvimento profissional do docente consiste em esforços para melhorar a qualidade do processo de ensino-aprendizagem e de desenvolver a cultura de aprendizagem ao longo da vida. A premissa de nosso embarque nesta comunidade foi de que, através da "reflexão mais ação", podíamos gerar uma prática em desenvolvimento sustentada no ciclo de aprendizagem de Kolb. A nossa comunidade de prática nos propiciou o levantamento de dúvidas, vistas pelas lentes dos nossos estudantes. Estas dúvidas possibilitaram a geração de ideias que podiam ser 
aplicadas ao ensino, experimentadas e sua viabilidade e implicações por nós partilhadas em contextos colegiais e ambiente democrático.

A auscultação que fizemos aos nossos estudantes, além de pertinente por familiarizar-nos com a sua avaliação de nosso desempenho, possibilitou a identificação de nossas necessidades de aprendizagem. Este foi um mecanismo de apropriação da nossa aprendizagem profissional, dado o valor que colocamos em nós, como aprendentes, com autonomia, poder, voz e responsabilidade sobre a nossa aprendizagem. Esta auscultação permitiu a identificação de aspetos positivos e outros que implicavam esforços de melhoria no nosso desempenho.

A nossa reflexão sobre a ação realizada na sequência do feedback do estudante mostra a emergência de três categorias, nomeadamente melhorias ocorridas, procedimentos para melhoria e áreas com necessidade de melhoria. Relativamente às melhorias ocorridas, observamos incremento no uso de material didático e na comunicação, que é uma das competências mais importantes que um docente deve ter. Quanto aos procedimentos empregues para o alcance das referidas melhorias, adotamos três estratégias metodológicas, a saber: interação com colegas, participação ativa do estudante e redução de críticas diretas. Demonstrando que a investigação-ação é um processo contínuo, em que mesmo que alcancemos um ponto de satisfação provisório, levantam-se novas questões ou prevalecem outras, duas áreas emergiram como sendo aquelas em que ainda necessitamos de melhorias, nomeadamente a diversificação de recursos didáticos e adoção de metodologias de ensino orientadas para turmas numerosas. Esta preocupação em particular, provavelmente seja devida à consciência dos crescentes desafios colocados por turmas numerosas, tais como a dificuldade de promover a aprendizagem ativa, colocar questões de ordem superior, diferenciar a atenção, gerir o barulho e a inquietude dos estudantes.

Podemos concluir que a organização da nossa comunidade de aprendizagem mostrou-se uma forma apropriada de desenvolver em nós a capacidade de aprendizagem ao longo da vida porque encorajou o senso de propriedade e propiciou o desenvolvimento da autorregulação na aprendizagem profissional. Contrariamente aos prescritivos programas de desenvolvimento profissional, nesta comunidade usufruímos todos da autonomia e responsabilidade pela planificação, implementação e avaliação de próprias ações de crescimento determinadas pela leitura que os estudantes fizeram de nossas práticas de lecionação. Pelo que, os resultados desta investigação-ação mostram que a nossa pretensão foi bem-sucedida, na medida que esta comunidade de aprendizagem ofereceu espaço e oportunidade para nos consciencializarmos sobre o que estamos a fazer na nossa prática de ensino.

\section{REFERÊNCIAS}

AFRICA DO SUL. MINISTRY OF EDUCATION. Gazetted the norms and standards for educators, Pretoria, 2000. Disponível em:

http://www.info.gov.za/speeches/2000/000229249p1003.htm Acesso em: 09 Nov. 2007.

BABBIE, Earl; MOUTON, Johann. The practice of social research. Cape Town: Oxford University Press, 2001. 
BARNETT, Ronald. Improving higher education: total quality care.

Buckingham: Society for Research into Higher Education \& Open University Press, 1992.

BISHOP, Russel. Freeing ourselves from neocolonial domination in research: A Kaupapa Maori approach to creating research. In: DENZIN, Norman Kent; LINCOLN, Yvonna Sessions. (Org). The sage handbook of qualitative research. $3^{\text {rd }}$ ed. Thousand Oaks: SAGE Publications, 2005, p. 191-215.

BOEKAERTS, Monique. Bringing about change in the classroom: Strengths and weaknesses of the self-regulated learning approach. Learning and Instruction, Amsterdam, v. 12, p. 589-604, 2002.

BOUD, David; KEOGH, Rosemary; WALKER, David. Reflection: Turning experience into learning. London: Kogan Page, 1985.

BROWN, John Seely; DUGUID, Paul. Organisational learning and communities-ofpractice: Toward a unified view of working, learning, and innovation. Organisation Science, Catonsville, v. 2, n. 1, p. 40-57, 1991.

CONNOLLY, Brid. Adult learning in groups. New York: Open University Press, 2008.

CONWAY, Paul Finbarr. Anticipatory reflection while learning to teach: From a temporally truncated to a temporally distributed model of reflection in teacher education. Teaching and Teacher Education, Amsterdam, v. 17, n. 2, p. 89-106, 2001.

COSTA, Antónia Flávia Moraes; SANTOS, Rayane Pedrosa. A prática pedagógica numa perspetiva reflexiva. XI Congresso Nacional de Educação. Anais... Curitiba, 2013. p. 15211. Anais eletrónicos. Disponível em https://educere.bruc.com.br/CD2013/pdf/8284_5837.pdf Acesso em: 25 Nov. 2020.

DEWEY, John. How we think. London: D.C. Heath \& Company, 1910.

EVANS, Linda. What is Teacher Development? Oxford Review of Education, Abingdon, v. 28, n. 1, p.123-137, 2002.

FOSNOT, Catherine Twomey. Constructivism: A psychological theory of learning. In FOSNOT, Catherine Twomey. (Org). Constructivism: Theory, perspectives and practice. New York: Teachers College press, 1996, p. 8-33.

HALEN-FABER, Christine van. Encouraging critical reflection in preservice teacher education: A narrative of a personal learning journey. New Directions for Adult and Continuing Education, New Jersey, v. 74, n. 1, p. 51-60, 1997. 
HAN, Bunyamin; TOSTEN, Rasim. (2016). In-class teacher-student communication according to high school students' perceptions. New Trends and Issues Proceedings on Humanities and Social Sciences, Nicosia, n. 11, p. 190- 198, 2016.

HARGREAVES, Andy; FULLAN, Michael. Mentoring in the new millennium. Theory into Practice, Abingdon, v. 39, n. 1, p. 50-56, 2000.

HARRISON, Jennifer; LAWSON, Tony; WORTLEY, Angela. Facilitating the professional learning of new teachers through critical reflection on practice during mentoring meetings. European Journal of Teacher Education, Abingdon, v. 28, n. 3, p. 267-292, 2005.

EKPO, Koko; AKPAN, Okon Edem; ESSIEN, Essien Ekpenyong; IMO-OBOT, Martin. Classroom climate and students' academic achievement in social studies in crossriver, Nigeria. African Research Review, Bahir Dar, v. 3, n. 4, p. 413-428, 2009.

KOLB, David Allen. Experiential learning: Experience as the source of learning and development. New Jersey: Prentice-Hall, 1984.

LAVE, Jean; WENGER, Etiene. Situated learning: Legitimal peripheral participation. New York: Cambridge University Press, 1991.

MALEK, Norazmah Suhailah Abdul; IBRAHIM, Noor Aaireen; ADNAN, Wan Nur Asyura Wan; RAHIM, Ramona Abd. Communication barriers between students and lecturers. LSP International Journal, Kuala Lumpur, v. 3, n. 2, p. 63-75, 2016.

MANDLATE, Ernesto Vasco. The staff development program at the Eduardo Mondlane University. Estudo de caso preparado para uma conferência intitulada "improving tertiary education in Sub-Saharian Africa: Things That Work". Accra, September 23-25, 2003.

MARAIS, Petro. We can't believe what we see: overcrowded classrooms through the eyes of student teachers. South African Journal of Education, Pretoria, v. 36, n. 2, p. 1-10, 2016.

MÁRIO, Mouzinho; FRY, Peter; LEVEY, Lisbeth; CHILUNDO, Arlindo. Higher education in Mozambique: A case study. Maputo: Imprensa Universitária, 2003.

MCKERNAN, James. Curriculum and imagination: process theory, pedagogy and action research. London: Routledge, 2008.

MCNIFF, Jean. Action research: Principles and practice. Hong Kong: MacMillan Education, 1988.

MCNIFF, Jean; WHITEHEAD, Jack. All you need to know about action research. London: SAGE Publications, 2006. 
MEZIROW, Jack. How critical reflection triggers transformative learning. In: MEZIROW, Jack. (Org). Fostering critical reflection in adulthood: A guide to transformative and emancipatory learning. California: Jossey-Bass, 1990, p.119.

MEZIROW, Jack. Transformative learning: Theory into practice. New Directions for Adult and Continuing Education, New Jersey, v. 74, p. 5-12, 1997.

MOÇAMBIQUE. Ministério de Educação e Cultura. Plano estratégico da educação e cultura 2006-2010/11. Maputo, 2006. Disponível em

<http://planipolis.iiep.unesco.org/sites/planipolis/files/ressources/mozambique_pee c_por.pdf> Acesso em: 12 fev. 2020.

MOÇAMBIQUE. Direcção de Coordenação do Ensino Superior. Plano operacional para implementação da segunda fase do Plano Estratégico para o Ensino Superior 2006-2010 em Moçambique. Maputo, 2006.

MOÇAMBIQUE. Resolução no 29/2009 de 21 de Maio. Aprova a Estratégia de formação de professores para o ensino superior. Maputo: Conselho de Ministros, Boletim da República, I série - Número 20, p. 3-7.

NICHOLS, Gill. Professional development, teaching, and lifelong learning: the implications for higher education. International Journal of Lifelong Education, Abingdon, v. 19, n. 4, p. 370-377, 2000.

PRYJMA, Marielda Ferreira; OLIVEIRA, Oseias Santos. O desenvolvimento profissional dos professores da educação superior: reflexões sobre a aprendizagem para a docência. Educação \& Sociedade, Campinas, v. 37, n.136, p. 841857, 2016.

HOGAN, Tracy; RABINOWITZ, Mitchell; CRAVEN, John. Representation in teaching: Inferences from research of expert and novice teachers. Educational

Psychologist, Abingdon, v. 38, n. 4, p. 235-247, 2003.

SCHÖN, Donald Alan. The reflective practitioner: How professionals think in action. New York: Basic Books, 1983.

SHULMAN, Lee. Those who understand: knowledge growth in teaching.

Educational Researcher, New York, v. 15, p.4-14, 1986.

SHULMAN, Lee. Knowledge and teaching: Foundations of the new reform. Harvard Educational Review, Massachusetts, v. 57, n. 1, p. 1-21, 1987.

TAYLOR, Maurice; ABASI, Ali; PINSENT-JOHNSON, Christine; EVANS, Karen. Collaborative learning in communities of literacy practice. Adult Basic Education and Literacy Journal, Syracuse, v. 1, n. 1, p. 4-11, 2007. 
VAN BOXTEL, Carla; VAN DER LINDEN, Jos; KANSELAAR, Gellof. Collaborative learning tasks and the elaboration of conceptual knowledge. Learning and Instruction, Amsterdam, v. 10, p. 311-330, 2000.

WINTER, Richard. Some principles and procedures for the conduct of action research. In: Zuber-Skerritt, Ortun. (Org). New directions in action research. London: Falmer Press, 1996, p. 13-27.

ZIMMERMAN, Barry. Self-regulated learning and academic achievement: An overview. Educational Psychologist, Abingdon, v. 25, n. 1, p. 3- 17, 1990.

Recebido em: 22 de agosto de 2020. Aceito em: 30 de novembro de 2020. Publicado em: 05 de janeiro de 2021. 